\title{
Worldwide implementation of the WHO Child Growth Standards
}

\author{
Mercedes de Onis ${ }^{1, *}$, Adelheid Onyango ${ }^{1}$, Elaine Borghi ${ }^{1}$, Amani Siyam ${ }^{1}$, \\ Monika Blössner ${ }^{1}$ and Chessa Lutter ${ }^{2}$, for the WHO Multicentre Growth Reference \\ Study Groupt \\ 'Department of Nutrition for Health and Development, World Health Organization, 20 Avenue Appia, 1211 \\ Geneva 27, Switzerland: ${ }^{2}$ WHO Region of the Americas, Washington, DC, USA
}

Submitted 3 November 2011: Final revision received 26 January 2012: Accepted 24 February 2012: First published online 12 April 2012

\begin{abstract}
Objective: To describe the worldwide implementation of the WHO Child Growth Standards ('WHO standards').

Design: A questionnaire on the adoption of the WHO standards was sent to health authorities. The questions concerned anthropometric indicators adopted, newly introduced indicators, age range, use of sex-specific charts, previously used references, classification system, activities undertaken to roll out the standards and reasons for non-adoption.

Setting: Worldwide.

Subjects: Two hundred and nineteen countries and territories.

Results: By April 2011, 125 countries had adopted the WHO standards, another twenty-five were considering their adoption and thirty had not adopted them. Preference for local references was the main reason for non-adoption. Weight-forage was adopted almost universally, followed by length/height-for-age (104 countries) and weight-for-length/height (eighty-eight countries). Several countries (thirty-six) reported newly introducing BMI-for-age. Most countries opted for sex-specific charts and the $Z$-score classification. Many redesigned their child health records and updated recommendations on infant feeding, immunization and other health messages. About two-thirds reported incorporating the standards into pre-service training. Other activities ranged from incorporating the standards into computerized information systems, to providing supplies of anthropometric equipment and mobilizing resources for the standards' roll-out.

Conclusions: Five years after their release, the WHO standards have been widely scrutinized and implemented. Countries have adopted and harmonized best practices in child growth assessment and established the breast-fed infant as the norm against which to assess compliance with children's right to achieve their full genetic growth potential.
\end{abstract}

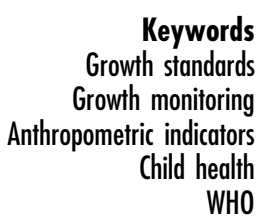

WHO
The assessment of growth in children is important for monitoring health status, identifying deviations from normality and determining the effectiveness of interventions ${ }^{(1)}$. The significance of timely detection of poor growth in early life resides in its association with adverse functional consequences, including poor cognition and educational performance, low adult wages, lost productivity and, when accompanied by excessive weight gain later in childhood, increased risk of nutrition-related chronic diseases ${ }^{(2)}$.

In 2004, we reported on child growth monitoring practices worldwide ${ }^{(3)}$ in preparation for the construction

$\dagger$ See Appendix for Members of the WHO Multicentre Growth Reference Study Group. of the WHO Child Growth Standards (hereafter referred to as the 'WHO standards'). Results of a global survey conducted in 178 countries on the use and interpretation of growth charts in national programmes showed that growth charts are universally used in paediatric care. Over half of the countries relied on the weight-for-age indicator alone, two-thirds used the National Center for Health Statistics/WHO (NCHS/WHO) reference, and 63\% of charts classified child growth based on percentiles. Reported problems with the use of growth charts were both conceptual and practical ${ }^{(3)}$.

Following the launch of the WHO standards in April $2006^{(4,5)}$, countries could choose to adopt the new standards and replace existing growth charts. Change implied 
a far-reaching shift in the way child growth is conceptualized as the WHO standards depict how children should grow, on average, in all countries, when properly fed and cared for, rather than merely describing how they grew at a particular time and place ${ }^{(4)}$. Five years after the release of the WHO standards, we conducted a follow-up survey to document their worldwide implementation and describe the changes in child growth monitoring practices that have occurred since our first report.

\section{Methods}

A questionnaire on implementation of the WHO standards was sent to national health authorities in 219 countries and territories through the WHO regional and country offices. The questionnaire was developed centrally and pre-tested for comprehensibility with nutrition advisers based in the six WHO regions. For clarity and to improve responsiveness, all questions had pre-coded answers and were kept as short as possible. The original English text was translated into French and Spanish, and the translated versions were checked for accuracy by native speakers of these languages with expertise in child growth assessment and monitoring. The questionnaire was accompanied by instructions for completing it and a cover message explaining the survey's objectives. In addition, countries and territories that had already adopted the WHO standards were requested to send samples of their new growth charts or new child health records. Ministry of Health technical staff members responsible for national maternal and child health programmes were asked to complete the questionnaire or forward it for response to a relevant national institution (e.g. the Centers for Disease Control and Prevention (CDC) in the USA) or the national paediatric association. Whenever clarifications were needed, we interacted with national technical staff to verify unclear responses.

The survey was conducted from November 2009 to April 2011. Information was collected on: the status of adoption and the main reasons for non-adoption in case of a negative response; the year of adoption; the anthropometric indicators adopted (weight-for-age (WFA), length/height-forage (LHFA), weight-for-length/height (WFLH), BMI-for-age (BMIFA), head circumference-for-age (HC), mid upper-arm circumference-for-age (MUAC), subscapular skinfold-forage (SS) and triceps skinfold-for-age (TS)); the age range covered by each indicator; whether or not the charts were sex-specific; if the indicator was newly introduced; the growth reference the WHO standards replaced (e.g. NCHS/WHO, CDC 2000, Tanner, Harvard, national or local reference); the classification system applied (i.e. Z-scores or percentiles); and what steps had been taken to roll out the standards. Respondents also reported on the type of information included on the child growth charts and on the main impediments to implementing the new standards once adopted. Countries also provided samples of new child health records/booklets.

The English version of the questionnaire was designed as a pdf interactive form using Adobe Acrobat $7 \cdot 0$ Professional (version $7 \cdot 1 \cdot 0$; Adobe Systems Incorporated), which allowed responses to be submitted electronically in xml (EXtensible Markup Language) format. These submissions were checked for consistency and incorporated directly into the master file (in Microsoft Excel format). The French and Spanish versions of the questionnaire were distributed in a Microsoft Word format that could be completed in soft or hard copy. Data from questionnaires that were returned in non-xml format (e.g. by fax, scan or courier) were keyed into the English interactive pdf template, validated and then exported via $\mathrm{xml}$ to the Microsoft Excel master file. Data were analysed using S-Plus (TIBCO S-Plus 8·2; TIBCO Software AG).

The WHO classification system was used to group the countries into geographical regions: AFR, African Region; AMR, Region of the Americas (North America, Latin America and the Caribbean); EMR, Eastern Mediterranean Region; EUR, European Region (Europe and Central Asia); SEAR, South-East Asia Region; and WPR, Western Pacific Region. The list of countries included in each of the WHO regions is available at http://www.who.int/ about/structure/en/index.html.

\section{Results}

Of the 219 countries and territories contacted, 180 (82\%) responded to the questionnaire. The countries and territories that did not send responses represent only $0.65 \%$ of the world's under- 5 population as they are mainly small islands in the Caribbean and the Pacific or European countries with small populations (e.g. Andorra, Liechtenstein, Monaco, San Marino). Of the responding countries, 125 had adopted the WHO standards, twenty-five were considering their adoption and thirty had not adopted them; representing, respectively, $75 \%, 17 \%$ and $7 \%$ of the world's under-5 population. Table 1 shows adoption status by geographical region. The countries that responded as not having adopted the standards by April 2011 were mainly in the European region ( $n$ 14), followed by Africa $(n 7)$, the Western Pacific ( $n$ 5) and three in the Americas (Fig. 1). Only one country in the South-East Asian region had not adopted them. Preference for local references was the main reason given for non-adoption: 13/14 countries in EUR, 4/5 in WPR, all three in AMR as well as the one country in SEAR. In AFR the two main reasons for non-adoption were lack of resources and the recent reprinting of charts in current use.

Table 2 presents the anthropometric indicators used for assessing growth based on the WHO standards. WFA was adopted almost universally, with only twelve of the 125 countries not adopting this indicator. LHFA was also adopted by a large number of countries ( $n$ 104), as was 
Table 1 Coverage of the survey and adoption status of the WHO Child Growth Standards by geographical region (April 2011)

\begin{tabular}{|c|c|c|c|c|c|c|}
\hline \multirow[b]{2}{*}{ Geographical region } & \multirow[b]{2}{*}{ No. of countries } & \multicolumn{2}{|c|}{ Response received } & \multirow[b]{2}{*}{ Adopted } & \multirow[b]{2}{*}{ Under consideration } & \multirow[b]{2}{*}{ Not adopted } \\
\hline & & No. of countries & $\%$ & & & \\
\hline AFR & 47 & 45 & 96 & 31 & 7 & 7 \\
\hline AMR & 49 & 37 & 75 & 33 & 1 & 3 \\
\hline EMR & 22 & 22 & 100 & 17 & 5 & 0 \\
\hline EUR & 57 & 45 & 79 & 23 & 8 & 14 \\
\hline SEAR & 11 & 11 & 100 & 10 & 0 & 1 \\
\hline WPR & 33 & 20 & 61 & 11 & 4 & 5 \\
\hline Total & 219 & 180 & 82 & 125 & 25 & 30 \\
\hline
\end{tabular}

AFR, African Region; AMR, Region of the Americas (North America, Latin America and the Caribbean); EMR, Eastern Mediterranean Region; EUR, European Region (Europe and Central Asia); SEAR, South-East Asia Region; WPR, Western Pacific Region.

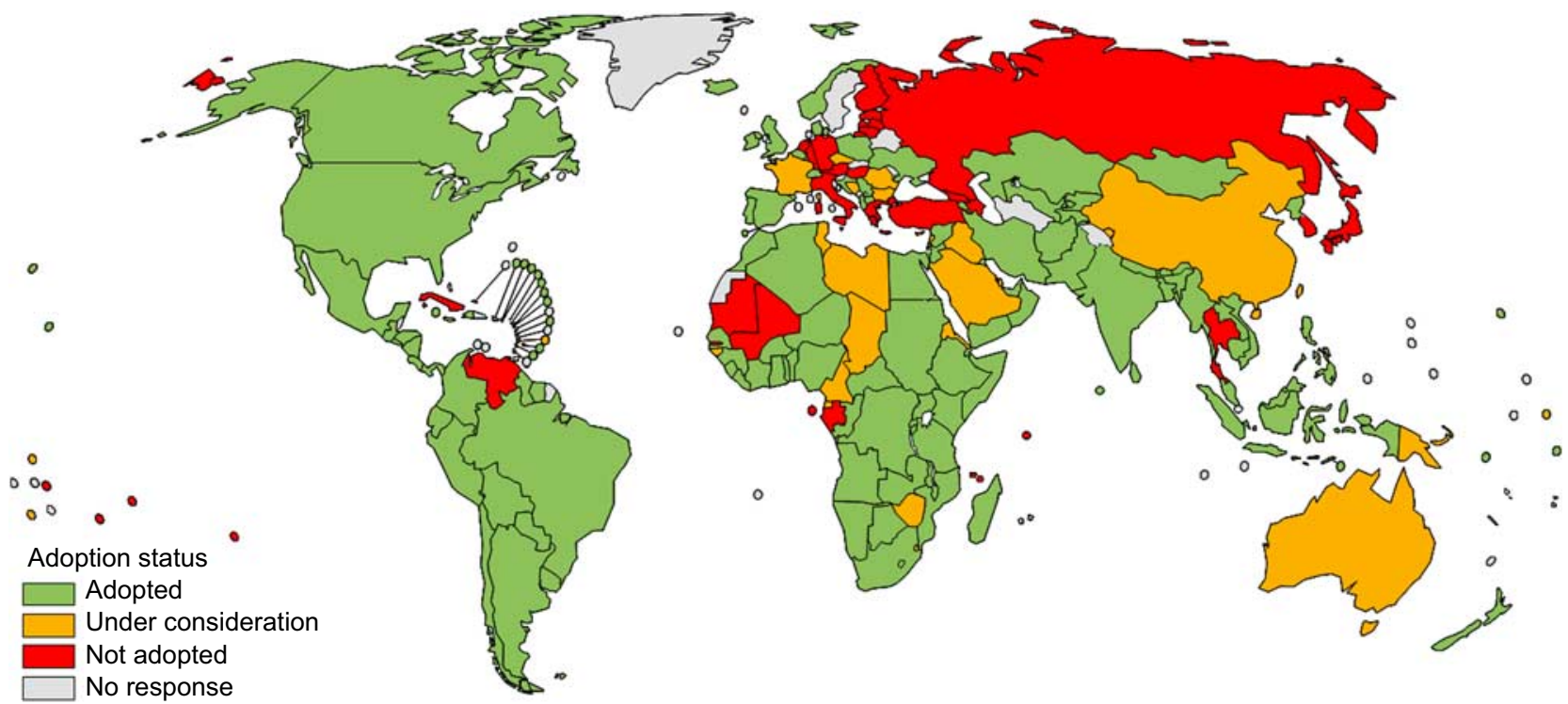

Fig. 1 Worldwide implementation of the WHO Child Growth Standards (April 2011)

Table 2 Anthropometric indicators used in monitoring child growth based on the WHO Child Growth Standards by geographical region (April 2011)

\begin{tabular}{|c|c|c|c|c|c|c|c|}
\hline Anthropometric indicator & $\begin{array}{l}\text { Countries adopted } \\
\text { (n 125) }\end{array}$ & $\begin{array}{l}\text { AFR } \\
(n 31)\end{array}$ & $\begin{array}{l}\text { AMR } \\
(n 33)\end{array}$ & $\begin{array}{l}\text { EMR } \\
(n 17)\end{array}$ & $\begin{array}{l}\text { EUR } \\
(n 23)\end{array}$ & $\begin{array}{l}\text { SEAR } \\
(n 10)\end{array}$ & $\begin{array}{l}\text { WPR } \\
(n 11)\end{array}$ \\
\hline WFA & 113 & 29 & 28 & 14 & 22 & 9 & 11 \\
\hline LHFA & 104 & 20 & 31 & 13 & 22 & 8 & 10 \\
\hline WFLH & 88 & 19 & 30 & 10 & 15 & 7 & 7 \\
\hline BMIFA & 50 & 5 & 10 & 4 & 21 & 4 & 6 \\
\hline $\mathrm{HC}$ & 57 & 7 & 22 & 6 & 14 & 2 & 6 \\
\hline MUAC & 17 & 6 & 3 & 2 & 2 & 1 & 3 \\
\hline SS & 2 & 0 & 0 & 0 & 1 & 0 & 1 \\
\hline TS & 2 & 0 & 0 & 0 & 1 & 0 & 1 \\
\hline
\end{tabular}

AFR, African Region; AMR, Region of the Americas (North America, Latin America and the Caribbean); EMR, Eastern Mediterranean Region; EUR, European Region (Europe and Central Asia); SEAR, South-East Asia Region; WPR, Western Pacific Region; WFA, weight-for-age; LHFA, length/height-for-age; WFLH, weight-for-length/height; BMIFA, BMI-for-age; HC, head circumference-for-age; MUAC, mid upper-arm circumference-for-age; SS, subscapular skinfold-forage; TS, triceps skinfold-for-age.

WFLH ( $n$ 88). BMIFA and HC were adopted by fifty and fifty-seven countries, respectively, mainly in the AMR and EUR regions. Many countries reported using the opportunity of implementing the WHO standards to introduce the monitoring of new indicators (e.g. forty-two countries introduced LHFA, thirty-eight WFLH, thirty-six BMIFA and twenty introduced HC). The other indicators (MUAC, TS and SS) were seldom adopted. 
The great majority of countries ( $n 121,97 \%$ ) adopting the WHO standards chose to use sex-specific charts, that is separate charts for boys and girls. Most countries adopted the full age range from birth to 60 months, with only a few exceptions that opted for birth to 24 months (one country) or 2 weeks to 4 years (two countries). On the growth reference in use prior to adoption of the WHO standards, eighty-six countries reported using the NCHS/WHO reference, twenty used a local reference, fourteen used the CDC 2000 growth charts, and a few countries used the Harvard or the Tanner standards. Seven countries were unable to identify the reference or standard in use prior to the adoption of the WHO standards. A few countries had been using more than one reference (i.e. different reference populations for different anthropometric indicators or in primary $v$. tertiary health-care facilities).

On the classification system selected by countries adopting the WHO standards, eighty-four (67\%) countries opted for the $Z$-score classification system while twenty-eight (22\%) preferred to use percentiles. The remaining countries reported using both classification systems for at least some of the anthropometric indicators.

Activities undertaken by countries as part of their implementation of the WHO standards are presented in Table 3. The great majority of adopting countries ( $n$ 104, $83 \%)$ redesigned their child health records to include the new charts and update recommendations on infant

Table 3 Summary of activities undertaken as part of the implementation of the WHO Child Growth Standards (April 2011)

\begin{tabular}{lc}
\hline Activity & $\begin{array}{c}\text { Countries adopted } \\
(n \text { 125) }\end{array}$ \\
\hline New child health card designed & 104 \\
Training conducted & 94 \\
Child growth assessment incorporated into & 80 \\
pre-service training & \\
Anthropometry equipment supplies purchased & 81 \\
Resource mobilization ongoing to support & 94 \\
$\quad$ implementation & 45 \\
Standards incorporated into computerized & \\
national health information system & 84 \\
Nutritional surveillance system has been/is & \\
being set up & \\
\hline
\end{tabular}

feeding, immunization and other health messages. As many as ninety-four (75\%) countries reported having formed a pool of national trainers that were cascading the training of the health workforce on the application of the WHO standards in their respective regions and districts. In addition, many countries ( $n 80,64 \%$ ) had incorporated the new standards into pre-service training for family doctors, clinical officers, nurses and other health personnel. Other activities ranged from incorporating the standards into computerized information systems, to providing new or additional supplies of anthropometric equipment, to mobilizing resources to support the rollout of the growth standards. The challenges encountered to the implementation process after official adoption of the standards are summarized in Table 4.

\section{Discussion}

In 2006 the WHO launched new growth standards for children irrespective of ethnicity, socio-economic status and feeding mode. By April 2011, at least 125 countries, representing $75 \%$ of the world's under- 5 population, had adopted the standards and were at varying stages of their implementation. It is very likely that some of the countries that were still considering implementing the standards when the survey was closed will have adopted them by the time the present paper is published.

In adopting the new standards many countries switched from using only WFA to using multiple indicators to better characterize growth patterns. Compared with an earlier report of growth monitoring practices ${ }^{(3)}$, there has been a significant rise in the use of LHFA (from fifty-nine countries in 2000 to 104 in 2011). That figure is likely to continue to increase given the importance of monitoring WFA during the first year of life, and thereafter monitoring height in addition to weight, because faltering patterns are clearly different for LHFA and WFA ${ }^{(6)}$ and short stature (or stunting) is associated with negative long-term outcomes ${ }^{(2,7)}$.

Similarly, many countries have introduced the indicator WFLH, which is essential to assessing severe acute malnutrition (i.e. wasting) as well as overweight and obesity. As many as thirty-six countries also introduced

Table 4 Challenges in the implementation of the WHO Child Growth Standards after adoption by geographical region

\begin{tabular}{|c|c|c|c|c|c|c|c|}
\hline \multirow[b]{2}{*}{ Impediment } & \multicolumn{7}{|c|}{ Countries having adopted the WHO standards by April 2011} \\
\hline & $\begin{array}{c}\text { AFR } \\
(n 31)\end{array}$ & $\begin{array}{c}\text { AMR } \\
(n 33)\end{array}$ & $\begin{array}{c}\text { EMR } \\
(n 17)\end{array}$ & $\begin{array}{c}\text { EUR } \\
(n 23)\end{array}$ & $\begin{array}{l}\text { SEAR } \\
(n 10)\end{array}$ & $\begin{array}{l}\text { WPR } \\
(n 11)\end{array}$ & $\begin{array}{c}\text { Total } \\
(n \text { 125) }\end{array}$ \\
\hline Other more urgent priorities & 4 & 7 & 2 & 10 & 1 & 4 & 28 \\
\hline Financial and other resource constraints & 26 & 29 & 11 & 18 & 4 & 8 & 96 \\
\hline Procedural impediments & 14 & 10 & 11 & 12 & 4 & 5 & 56 \\
\hline Coordination challenges & 16 & 13 & 10 & 12 & 3 & 4 & 58 \\
\hline Others & 6 & 7 & 3 & 5 & 1 & 1 & 23 \\
\hline
\end{tabular}

AFR, African Region, AMR, Region of the Americas (North America, Latin America and the Caribbean), EMR, Eastern Mediterranean Region, EUR, European Region (Europe and Central Asia), SEAR, South-East Asia Region, WPR, Western Pacific Region. 
BMIFA, another important indicator for monitoring the growing epidemic of childhood obesity. In addition, BMIFA provides continuity with the monitoring of overweight and obesity in the 5-19 age range ${ }^{(8)}$. It is worth noting that in pre-school children, because WFLH and BMIFA provide similar information ${ }^{(9)}$, there is no need to monitor both indicators.

Another improvement relates to the use of separate charts for boys and girls. Most countries that in the earlier survey ${ }^{(3)}$ reported using combined charts, have opted to use separate charts for boys and girls. Only four countries reported continued use of sexes-combined charts, mainly because of printing costs.

Compared with the previous report ${ }^{(3)}$ many countries have switched from the percentile or per cent-of-median system to use the $Z$-score system for nutritional status classification. Z-scores are preferred because they permit clinical tracking of patients whose anthropometric classification lies beyond the measurable limits of the percentile range, as happens in the case of severely undernourished or obese children. Occasionally, countries report using both systems depending on the purpose, e.g. percentile charts for clinical use and $Z$-scores for public health purposes. With only a few exceptions, countries reported using the WHO charts for the age range birth to 5 years, and several ( $n$ 16) also have adopted the WHO 2007 growth reference for school-aged children and adolescents to monitor the nutritional status of children aged 5 to 19 years $^{(8)}$.

The implementation of the WHO standards has taken different pathways depending on national health systems and decision-making processes. In almost all cases, the standards have been adopted nationwide. However, for countries with decentralized systems like Australia, Belgium and Spain, some parts of the country have adopted the WHO standards while others continue to use previous charts. Generally, most countries with decentralized administrations decided to adopt the WHO standards nationally, thus harmonizing the assessment of child growth in the country.

The scrutiny that the WHO standards have undergone is without precedent in the history of developing and applying growth assessment tools, whether national or international. Governments set up committees ${ }^{(10-12)}$ to scrutinize the new standards before deciding to adopt them and professional groups that use anthropometric indicators conducted thorough examination of the standards. Through this process concerns were raised ${ }^{(13-16)}$ and strengths were noted ${ }^{(17-27)}$. The detailed evaluation made it possible to quantify the impact of the new standards on estimates of prevalence of malnutrition ${ }^{(28-34)}$ and their implications for child health programmes ${ }^{(35-58)}$.

Rolling out new growth charts is a complex task affecting all levels of a national health system. It concerns not only clinicians and health practitioners but also nutritionists, dietitians, public health specialists, child and health advocates, parents/caregivers and researchers.
A great deal of coordination is necessary among all these stakeholders to ensure a smooth implementation. Many countries have redesigned their child health records, upgraded their anthropometric equipment, and retrained health staff to incorporate the WHO standards into their work. The WHO standards have also been incorporated into pre-service training programmes for medical and nursing professionals in several countries. Some countries have used the opportunity of switching to the new standards to raise awareness of the importance of child growth monitoring and redesign their surveillance systems to enhance decision making. Each aspect has required a considerable effort to implement and called for a reallocation of resources.

The introduction of new indicators such as BMIFA or length/height-based indicators posed considerable practical challenges with potential for measurement error and misclassification of children. A large-scale training programme was set in place by WHO, in coordination with UNICEF, that resulted in a network of facilitators to support training and other technical aspects of the standards' implementation at regional and country level. The training package ${ }^{(59)}$ emphasizes the importance of accurate measurement, plotting and interpretation for the correct identification of growth problems. If a child has a growth problem or trend towards a growth problem, the causes should be determined to take action to address them. Growth assessments that are not supported by appropriate response actions to prevent and treat excessive or inadequate growth are not effective in improving child health.

The implementation of the growth standards at country level required resources to design and produce new child health records, print large quantities of the new charts, buy anthropometric equipment (e.g. weighing scales) or produce them locally (i.e. height boards), translate documentation and tools (e.g. the training materials), and conduct national training workshops. Resource constraints (e.g. under-staffing in primary health-care facilities and shortage of equipment) have been an important bottleneck. UNICEF and other key partners played significant roles in supporting the standards' implementation but there continues to be a need for support since significant costs are involved in the mass procurement of anthropometric equipment, in printing new charts, training health personnel, and especially in developing or strengthening programmes to deal with the growth problems identified through the application of the standards.

\section{Acknowledgements}

The work was supported by WHO and the Bill \& Melinda Gates Foundation. The authors are WHO staff members. The authors alone are responsible for the views expressed in this publication and they do not necessarily represent the 
decisions or policies of the WHO. No author had a personal or financial conflict of interest. M.d.O. conceptualized the paper, guided the analyses and wrote the first draft of the paper. A.O. and A.S. developed the questionnaire and conducted the survey. E.B. analysed the data and wrote up the methods. M.B. and C.L. participated in the implementation of the growth standards. All authors participated in the interpretation of results, preparation of the manuscript and approved its final version. The authors are grateful to UNICEF, the governments of WHO Member States, non-governmental organizations and the numerous individuals who have participated in the roll-out of the WHO Child Growth Standards and facilitated their rapid global implementation.

\section{References}

1. World Health Organization (1995) Physical Status: The Use and Interpretation of Anthropometry. Report of a WHO Expert Committee. WHO Technical Report Series no. 854. Geneva: WHO.

2. Victora CG, Adair L, Fall C et al. (2008) Maternal and child undernutrition: consequences for adult health and human capital. Lancet 371, 340-357.

3. de Onis M, Wijnhoven TMA \& Onyango AW (2004) Worldwide practices in child growth monitoring. J Pediatr 144, 461-465.

4. WHO Multicentre Growth Reference Study Group (2006) WHO Child Growth Standards based on length/height, weight and age. Acta Paediatr Suppl 450, 76-85.

5. World Health Organization (2006) WHO Child Growth Standards: Length/Height-for-Age, Weight-for-Age, Weightfor-Length, Weight-for-Height and Body Mass Index-forAge: Methods and Development. Geneva: WHO.

6. Victora CG, de Onis M, Hallal PC et al. (2010) Worldwide timing of growth faltering: revisiting implications for interventions using the World Health Organization growth standards. Pediatrics 125, e473-e 480.

7. de Onis M, Blössner M \& Borghi E (2012) Prevalence and trends of stunting among pre-school children, 1990-2020. Public Health Nutr 15, 142-148.

8. de Onis M, Onyango AW, Borghi E et al. (2007) Development of a WHO growth reference for school-aged children and adolescents. Bull World Health Organ 85, 660-667.

9. de Onis M, Blössner M \& Borghi E (2010) Global prevalence and trends of overweight and obesity among preschool children. Am J Clin Nutr 92, 1257-1264.

10. Scientific Advisory Committee on Nutrition/Royal College of Paediatrics and Child Health (2011) Application of the WHO Growth Standards in the UK, 2007. Report prepared by the Joint SACN/RCPCH Expert Group on Growth Standards. http://www.sacn.gov.uk/pdfs/sacn.rcpch_who_ growth_standards_report_final.pdf (accessed September 2011).

11. Centers for Disease Control and Prevention (2010) Use of World Health Organization and CDC Growth Charts for children aged 0-59 months in the United States. MMWR Recomm Rep 59, 1-15.

12. Dietitians of Canada, Canadian Paediatric Society, College of Family Physicians of Canada \& Community Health Nurses of Canada (2010) Promoting optimal monitoring of child growth in Canada: using the new WHO growth charts. Can J Diet Pract Res 71, e1-e3.

13. Centers for Disease Control and Prevention (2009) Impact of new WHO growth standards on the prevalence of acute malnutrition and operations of feeding programs - Darfur, Sudan, 2005-2007. MMWR Morb Mortal Wkly Rep 58, 591-594.

14. Seal A \& Kerac M (2007) Operational implications of using 2006 World Health Organization growth standards in nutrition programmes: secondary data analysis. BMJ 334, 733.

15. Fernández MA, Delchevalerie P \& Van Herp M (2010) Accuracy of MUAC in the detection of severe wasting with the new WHO growth standards. Pediatrics 126, e195-e201.

16. Binns C \& Lee M (2006) Will the new WHO growth references do more harm than good? Lancet 368, 1868-1869.

17. Dale NM, Grais RF, Minetti A et al. (2009) Comparison of the new World Health Organization growth standards and the National Center for Health Statistics growth reference regarding mortality of malnourished children treated in a 2006 nutrition program in Niger. Arch Pediatr Adolesc Med 163, 126-130.

18. Lapidus N, Luquero FJ, Gaboulaud V et al. (2009) Prognostic accuracy of WHO growth standards to predict mortality in a large-scale nutritional program in Niger. PLOS Med 6, e1000039.

19. Vesel L, Bahl R, Martines J et al. (2010) Use of new World Health Organization child growth standards to assess how infant malnutrition relates to breastfeeding and mortality. Bull World Health Organ 88, 39-48.

20. Isanaka S, Villamor E, Shepherd S et al. (2009) Assessing the impact of the introduction of the World Health Organization growth standards and weight-for-height $z$-score criterion on the response to treatment of severe acute malnutrition in children: secondary data analysis. Pediatrics 123, e54-e59.

21. de Onis M, Onyango AW, Borghi E et al. (2006) Comparison of the WHO Child Growth Standards and the NCHS/WHO international growth reference: implications for child health programmes. Public Health Nutr 9, 942-947.

22. Saha KK, Frongillo EA, Alam DS et al. (2009) Use of the new World Health Organization child growth standards to describe longitudinal growth of breastfed rural Bangladeshi infants and young children. Food Nutr Bull 30, 137-144.

23. Bois C, Servolin J \& Guillermot G (2010) Usage comparé des courbes de l'Organisation mondiale de la santé et des courbes françaises dans le suivi de la croissance pondérale des jeunes nourrissons. Arch Pediatr 17, 1035-1041.

24. Agostoni C, Braegger C, Decsi T et al. (2009) Breastfeeding: a commentary by the ESPGHAN Committee on Nutrition. J Pediatr Gastroenterol Nutr 49, 112-125.

25. Kerac M, Blencowe H, Grijalva-Eternod C et al. (2011) Prevalence of wasting among under 6-month-old infants in developing countries and implications of new case definitions using WHO growth standards: a secondary data analysis. Arch Dis Child 96, 1008-1013.

26. van Dijk CE \& Innis SM (2009) Growth-curve standards and the assessment of early excess weight gain in infancy. Pediatrics 123, 102-108.

27. Maalouf-Manasseh Z, Metallinos-Katsaras E \& Dewey KG (2011) Obesity in preschool children is more prevalent and identified at a younger age when WHO growth charts are used compared with CDC charts. J Nutr 141, 1154-1158.

28. Black RE, Allen LH, Bhutta ZA et al. (2008) Maternal and child undernutrition: global and regional exposures and health consequences. Lancet 371, 243-260.

29. Nash A, Secker D, Corey M et al. (2008) Field testing of the 2006 World Health Organization growth charts from birth to 2 years: assessment of hospital undernutrition and overnutrition rates and the usefulness of BMI. $J$ Parenter Enteral Nutr 32, 145-153.

30. Prost MA, Jahn A, Floyd S et al. (2008) Implication of new WHO growth standards on identification of risk factors and 
estimated prevalence of malnutrition in rural Malawian infants. PLoS One 3, e2684.

31. Mei Z, Ogden CL, Flegal KM et al. (2008) Comparison of the prevalence of shortness, underweight, and overweight among US children aged 0 to 59 months by using the CDC 2000 and the WHO 2006 growth charts. J Pediatr 153, 622-628.

32. Roelants M, Hauspie R \& Hoppenbrouwers K (2010) Breastfeeding, growth and growth standards: performance of the WHO growth standards for monitoring growth of Belgian children. Ann Hum Biol 37, 2-9.

33. Marín Gabriel MA, Pallás Alonso CR, De La Cruz Bértolo J et al. (2009) Age of sitting unsupported and independent walking in very low birth weight preterm infants with normal motor development at 2 years. Acta Paediatr $\mathbf{9 8}$, 1815-1821

34. Nuruddin R, Lim MK, Hadden WC et al. (2008) Comparison of estimates of under-nutrition for pre-school rural Pakistani children based on the WHO standard and the National Center for Health Statistics (NCHS) reference. Public Health Nutr 12, 716-722.

35. World Health Organization (2009) WHO Child Growth Standards and the Identification of Severe Acute Malnutrition in Infants and Children. A Joint Statement by the World Health Organization and the United Nations Children's Fund. Geneva: WHO.

36. Kerac M, Egan R, Mayer S et al. (2009) New WHO growth standards: roll-out needs more resources. Lancet 374, 100-102.

37. de Onis M, Borghi E, Siyam A et al. (2011) Comparison of the World Health Organization growth velocity standards with existing US reference data. Pediatrics 128, e18-e26.

38. van Buuren S \& van Wouwe JP (2008) WHO Child Growth Standards in action. Arch Dis Child 93, 549-551.

39. Wright C, Lakshman R, Emmett $\mathrm{P}$ et al. (2008) Implications of adopting the WHO 2006 Child Growth Standard in the UK: two prospective cohort studies. Arch Dis Child 93, 566-569.

40. Michaelsen KF (2010) WHO Growth Standards - should they be implemented as national standards? J Pediatr Gastroenterol Nutr 51, Suppl. 3, S151-S152.

41. Van de Broeck J, Willie D \& Younger N (2009) The World Health Organization child growth standards: expected implications for clinical and epidemiological research. Eur J Pediatr 168, 247-251.

42. Duggan MB (2010) Anthropometry as a tool for measuring malnutrition: impact of the new WHO growth standards and reference. Ann Trop Paediatr 30, 1-17.

43. Mei Z \& Grummer-Strawn LM (2007) Standard deviation of anthropometric Z-scores as a data quality assessment tool using the 2006 WHO growth standards: a cross country analysis. Bull World Health Organ 85, 441-448.

\section{Appendix}

\section{WHO Multicentre Growth Reference Study Group}

Coordinating Team: Mercedes de Onis (Study Coordinator), Adelheid Onyango, Elaine Borghi, Amani Siyam (Department of Nutrition, WHO).

Executive Committee: Cutberto Garza (Chair), Mercedes de Onis, Jose Martines, Reynaldo Martorell, Cesar G. Victora, Maharaj K. Bhan.

Steering Committee: Coordinating Centre (WHO, Geneva): Mercedes de Onis, Jose Martines, Adelheid Onyango, Alain Pinol. Investigators (by country): Cesar G. Victora,
44. Cole TJ (2008) The WHO child growth standards and current Western growth references. Breastfeed Rev 16, $13-16$.

45. Rolland-Cachera MF \& Péneau S (2009) Nouveaux standards de croissance OMS: conséquences sur l'interprétation des mesures. Arch Pediatr 16, 737-738.

46. Wang Y, Chen C \& He W (2007) Analysis of children's nutritional status based on WHO children growth standard in China. J Hyg Res 36, 203-206.

47. Hui LL, Schooling CM, Cowling BJ et al. (2008) Are universal standards for optimal infant growth appropriate? Evidence from a Hong Kong Chinese birth cohort. Arch Dis Child 93, 561-565.

48. Prinja S, Thakur JS \& Bhatia SS (2009) Pilot testing of WHO Child Growth Standards in Chandigarh: implications for India's child health programmes. Bull World Health Organ 87, 116-122.

49. Mamidi RS, Shidhaye P, Radhakrishna KV et al. (2011) Pattern of growth faltering and recovery in under-5 children in India using WHO Growth Standards - a study on First and Third National Family Health Survey. Indian Pediatr, (Epublication ahead of print version)

50. de Onis M \& Woynarowska B (2010) WHO Child Growth Standards for children $0-5$ years and the possibility of their implementation in Poland. Med Wieku Rozwoj 14, 87-94.

51. Guerra A (2009) As curvas de crescimento da Organizacão Mundial de Saúde. Acta Pediatr Port 40, XLI-XLV.

52. Júlíusson PB, Roelants M, Hoppenbrouwers K et al. (2011) Growth of Belgian and Norwegian children compared to the WHO growth standards: prevalence below -2 and above $+2 \mathrm{SD}$ and the effect of breastfeeding. Arch Dis Child 96, 916-921.

53. Wright CM, Williams AF, Elliman D et al. (2010) Using the new UK-WHO growth charts. BMJ 340, c1140.

54. Wright CM, Inskip HM, Godfrey K et al. (2011) Monitoring head size and growth using the new UK-WHO growth standard. Arch Dis Child 96, 386-388.

55. Greer FR (2008) Time to step up to the plate: adopting the WHO 2006 growth curves for US infants. J Pediatr 153, 592-594.

56. Hoey L \& Pelletier DL (2011) The management of conflict in nutrition policy formulation: choosing growth-monitoring indicators in the context of dual burden. Food Nutr Bull 32, 2 Suppl., S82-S91.

57. Ramachandran P (2007) Adoption of WHO growth standards (2006): issues and implications. NFI Bull 28, 1-6.

58. Ramachandran P \& Gopalan HS (2011) Assessment of nutritional status in Indian preschool children using WHO 2006 Growth Standards. Indian J Med Res 134, 47-53.

59. World Health Organization (2008) Training Course on Child Growth Assessment. Geneva: WHO; available at http://www.who.int/childgrowth/training/en/

Cora Luiza Araújo (Brazil); Anna Lartey, William B. Owusu (Ghana); Maharaj K. Bhan, Nita Bhandari (India); Kaare R. Norum, Gunn-Elin Aa. Bjoerneboe (Norway); Ali Jaffer Mohamed (Oman); Kathryn G. Dewey (USA). Representatives of UN agencies: Cutberto Garza (United Nations University), Krishna Belbase (UNICEF).

Advisory Group: Maureen Black, Wm. Cameron Chumlea, Tim Cole, Edward Frongillo, Laurence GrummerStrawn, Reynaldo Martorell, Roger Shrimpton, Jan Van den Broeck.

Participating countries and investigators: Brazil: Cora Luiza Araújo, Cesar G. Victora, Elaine Albernaz, Elaine 
Tomasi, Rita de Cássia Fossati da Silveira, Gisele Nader (Departamento de Nutrição and Departamento de Medicina Social, Universidade Federal de Pelotas; and Núcleo de Pediatria and Escola de Psicologia, Universidade Católica de Pelotas). Ghana: Anna Lartey, William B. Owusu, Isabella Sagoe-Moses, Veronica Gomez, Charles Sagoe-Moses (Department of Nutrition and Food Science, University of Ghana; and Ghana Health Service). India: Nita Bhandari, Maharaj K. Bhan, Sunita Taneja, Temsunaro Rongsen, Jyotsna Chetia, Pooja Sharma, Rajiv Bahl (All India Institute of Medical Sciences). Norway: Gunn-Elin Aa. Bjoerneboe, Anne Baerug, Elisabeth Tufte, Kaare R. Norum, Karin Rudvin, Hilde Nysaether (Directorate of Health and Social
Affairs; National Breastfeeding Centre, Rikshospitalet University Hospital; and Institute for Nutrition Research, University of Oslo). Oman: Ali Jaffer Mohamed, Deena Alasfoor, Nitya S. Prakash, Ruth M. Mabry, Hanadi Jamaan Al Rajab, Sahar Abdou Helmi (Ministry of Health). USA: Kathryn G. Dewey, Laurie A. NommsenRivers, Roberta J. Cohen, M. Jane Heinig (University of California, Davis).

WHO Regional Offices staff: Ayoub Al-Jawaldeh (EMR), Kunal Bagchi (SEAR), Tomasso Cavalli-Sforza (WPR), Ferima Coulibaly-Zerbo (AFR), Aichatou Diawara Gbaguidi (AFR), Abel Dushimimana (AFR), Chessa Lutter (AMR), Charles Sagoe-Moses (AFR), Ursula Trubswasser (AFR), Trudy Wijnhoven (EUR). 